\title{
LARGE DOUBLY SEPTATED CONCHA BULLOSA: AN UNUSUAL ANATOMIC VARIATION
}

\author{
Aleksandar Perić, Svjetlana Matković-Jožin, Nenad Baletić
}

Military Medical Academy, 11040 Belgrade, Serbia: Clinic for Otorhinolaryngology

\begin{abstract}
Summary: Partial or total pneumatization of the middle turbinate is called concha bullosa. It's one of the most common anatomic variations of the lateral nasal wall. The exact reason of such pneumatization is not known. It can originate from the frontal recess, middle meatus, sinus lateralis or, less frequently, from the posterior ethmoid cells. Concha bullosa remains usually asymptomatic. However, an extensively pneumatized middle turbinate may constitute space-occupying mass, and thus, it may cause nasal obstruction. We report an extremely rare case of a patient with a large, doubly septated concha bullosa with four different sources of aeration.
\end{abstract}

Key words: Concha bullosa; Septated; Middle turbinate; Nasal obstruction

\section{Introduction}

The development of computed tomography (CT) technique results in the advance in visualisation of the anatomic structures of the lateral nasal wall. It allows the anatomic variations of this region to be identified precisely. Concha bullosa $(\mathrm{CB})$ is pneumatized middle turbinate and it's the most commonly seen anatomic variant of the lateral nasal wall. The detailed anatomy of the $\mathrm{CB}$ has first been described by Zuckerkandl (15). In anatomical studies, CB has been noted in $5-20 \%$ of the nasal specimens (5). However, it was found in $34 \%$ of patients having CT for the evaluation of symptomatic sinus disease (14).

Different types of anatomic variations of the middle turbinate have been described in the literature as pneumatized, lateralized, hypoplastic and hypertrophic, paradoxally curved, secondary and accessory, bifurcate and trifurcate middle turbinate $(2,6,8,9,11)$. Septated CB has been rarely seen in the rhinological practice. To our knowledge, we present the second case of a patient with doubly septated CB. The first one was described by Yanagisawa et al. (13).

\section{Case report}

A 26-year-old male came to our clinic with severe nasal obstruction and intermittent mid-facial pressure. Anterior rhinoscopy and endoscopic examination revealed hypertrophy of the left middle turbinate and septal deviation (spur) to the right side (Fig. 1). The nasal mucosa seemed healthy. A coronal plane CT demonstrated an extensive pneumatization of the left middle concha with a lateral os- tium communicating with the middle nasal meatus and a superior-lateral ostium communicating with the sinus lateralis (Fig. 2a). The large CB superiorly attached directly to the skull base and laterally to the lamina papyracea. Next $\mathrm{CT}$ cross-section showed that CB was septated. The floor of the left orbit presented with an orbitoethmoid (Haller) cell (Fig. 2b). What is more interesting, axial CT scan showed anterior and posterior thin bony septum inside the $\mathrm{CB}$, so $\mathrm{CB}$ cavity was divided into the anterior, intermedial and posterior cell. The anterior CB septum was very thin, so it seemed to be incomplete (Fig. 2c). The right maxillary sinus was incompletely septated whereas in the left one, we could

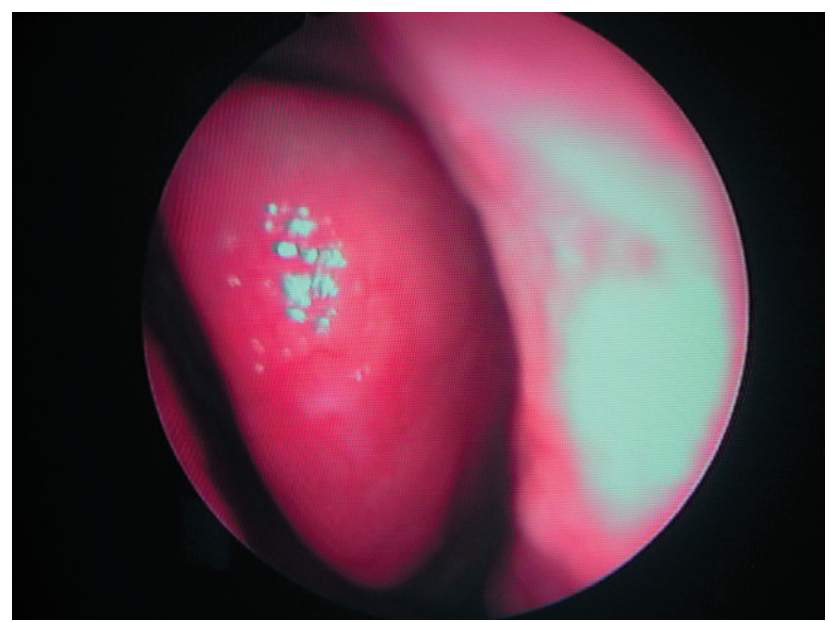

Fig. 1: Endoscopic view of the left-sided hypertrophic middle concha. 


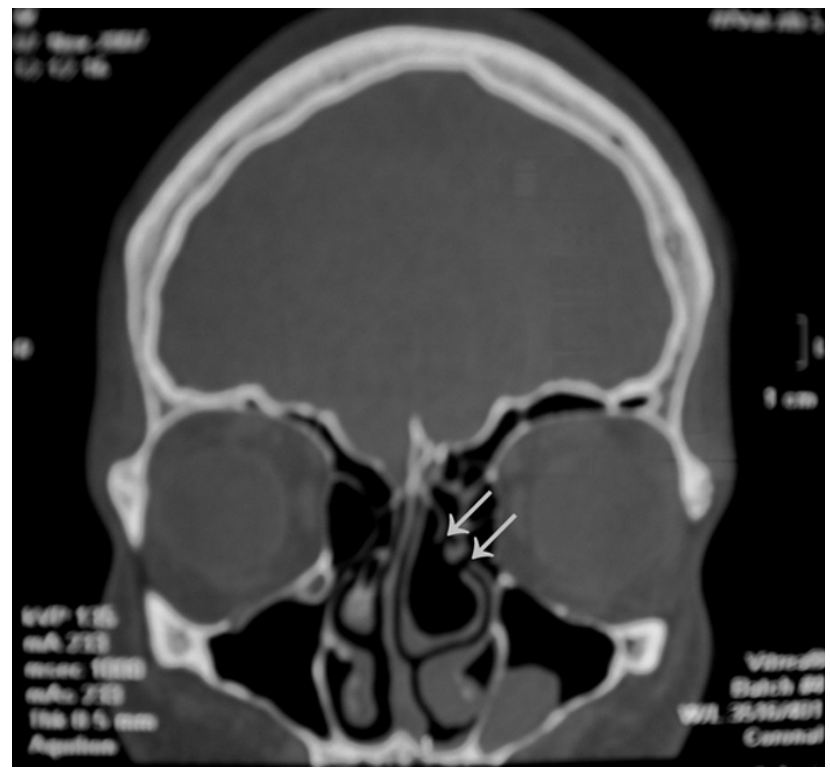

Fig. 2a: Coronal CT scan demonstrating an extensive CB with a lateral ostium communicating with the middle meatus (arrow head) and a superolateral ostium communicating with the sinus lateralis (arrow head).

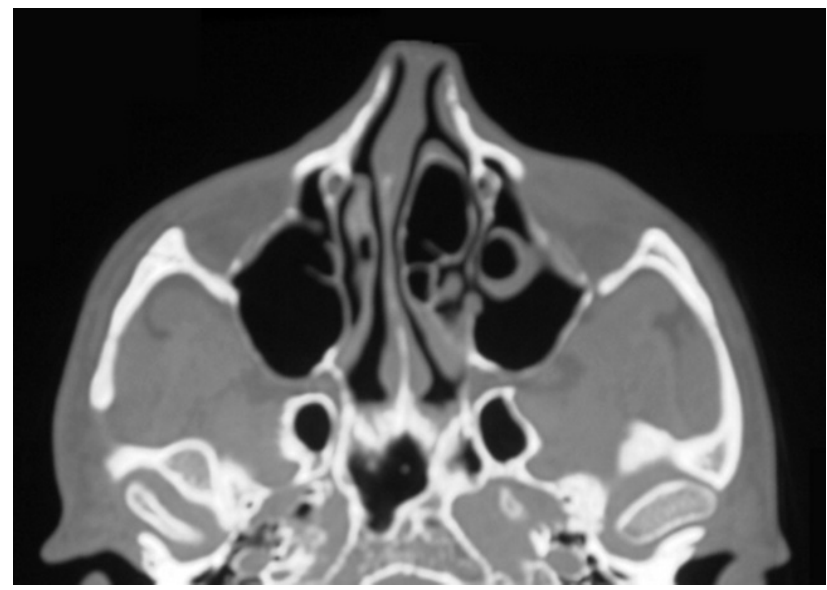

Fig. 2c: Axial CT scan showing anterior and posterior bony septum within the $\mathrm{CB}$.

see a retential cyst on the antral floor. Reduced total intranasal airflow was confirmed by anterior active rhinomanometry (AAR).

The patient underwent transnasal endoscopic surgery following septoplasty under general anestesia. A vertical incision was made on the anterior CB wall and the lateral lamella was resected. Finally, the bony septa were removed from the CB cavity. Mucosa of the uncinate process and the CB cavity seemed healthy (Fig. 3). The patient's nasal breathing improved immediately after surgery, which was showed by AAR as better nasal airflow. He was free of nasal blockage and feelings of pressure during 12-month follow-up.

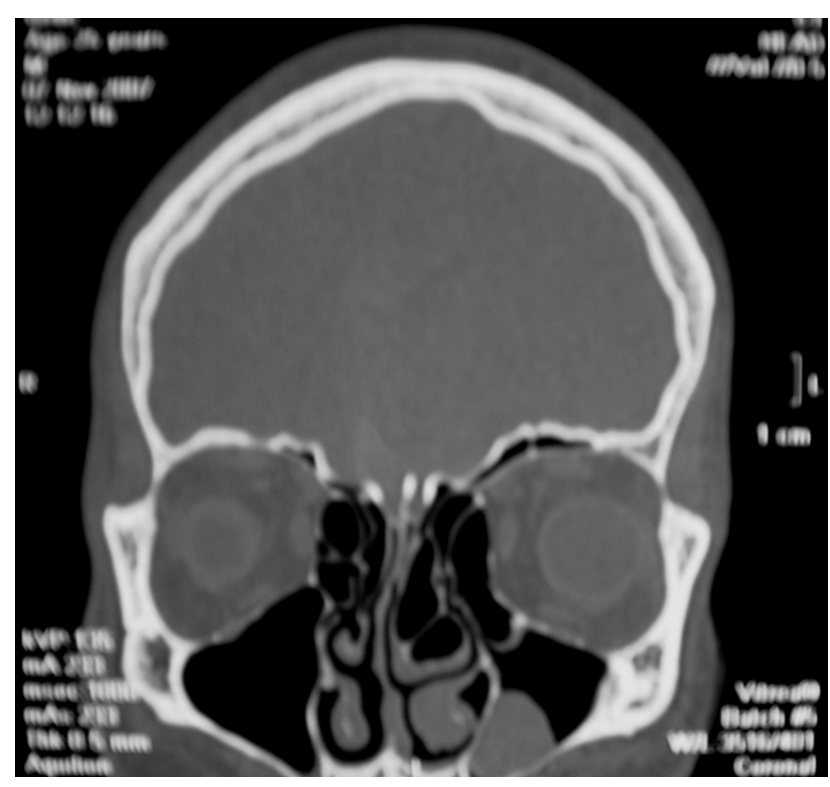

Fig. 2b: Coronal CT scan showing a bony septum inside the CB cavity. Retention cyst inside the left maxillary sinus.

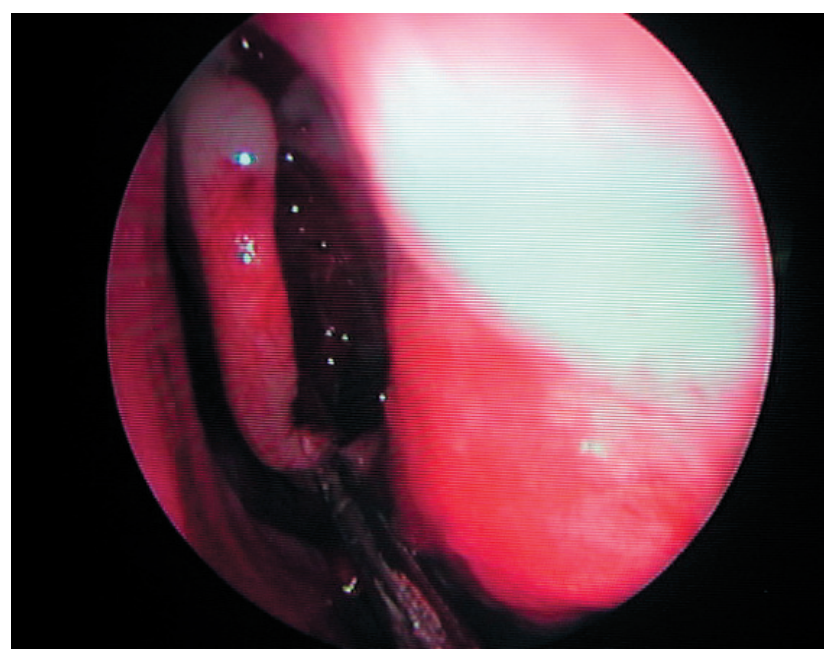

Fig. 3: Endoscopic view of the CB after resection of its lateral portion. Mucosa of the uncinate process seems healthy.

\section{Discussion}

The middle turbinate is an important landmark of the lateral nasal wall, which forms the medial wall of the ethmoid sinus. It is associated with many functions of the nasal cavity, including olfaction, humidification, lubrication of the upper airways, regulation of airflow and temperature and filtration (10). The middle concha is formed by the medial part of the ethmoid bone. As it elongates in the nasal cavity, anterior-superior stabilisation is provided by the cribriform plate and posterior and lateral stabilisation is provided by the lamina papyracea $(7,10)$. The bony structure that allows attachment to the lamina papyracea is called the 
basal lamella. Basal lamella divides the ethmoid air cells into the anterior and posterior group (7). Pneumatization of the middle turbinate is an extension of the normal pneumatization of the ethmoid sinus $(7,10)$. Nasal turbinates can be first identified during the $8-10$ week of fetal life as outgrowths from the lateral nasal wall. The outgrowths form a series of ridges referred to as ethmoturbinals $(5,12)$. Initially, there are six ridges. Some of them develop into permanent structures on the lateral nasal wall, while the remaining ones fuse or disappear. The middle turbinate develops from the third ridge $(5,12)$. The exact reason of pneumatization of the middle concha is not known (1). It has been demonstrated that pneumatization of the middle turbinate originate from the frontal recess, middle meatus, sinus lateralis, ethmoid infundibulum or the agger nasi region $(5,7,12)$. The middle concha also may begin to be pneumatized by the posterior ethmoid cells (1). Bolger et al. (4) have divided the pneumatization of the middle turbinate into three groups: lamelar type is the pneumatization of the vertical lamella; bulbous type is the pneumatization of the bulbous segment; pneumatization of both the lamellar and bulbous parts is called extensive CB.

In this case, we presented an extremely rare variant of an extensive pneumatization. Large $\mathrm{CB}$ was divided into three air cells by the two bony septa. The anterior cell communicated with two spaces: laterally with the middle meatus and superior-laterally with the sinus lateralis. The intermedial cell drained into the frontal recess and the posterior one seemed to drain into the one of the posterior ethmoid cells. Clearly, there could be different sources of pneumatization in middle turbinate, resulting in three air cells within. Ventilation of the air cells came from the area in which the pneumatization appeared and mucociliary clearence seemed to be similar. However, we did not know which structure had the bigger part in pneumatization of anterior cell: middle meatus or sinus lateralis.

Some studies suggest that CB may have a role in aetiology of chronic rhinosinusitis due to stenosis of the ostiomeatal complex (OMC), while some other suggest that there is no statistically significant relationship between the presence of CB and ethmoid, maxillary and frontal sinus disease $(1,7)$. Endoscopic examination did not show any signs of sinus disease in our patient. By the CT scan, we could find only retention cyst inside the left maxillary sinus. Bhattacharyya (3) has shown that maxillary sinus retention cyst do not reflect persistent obstructive pathology in $\mathrm{OMC}$, and are not associated with potentially obstructive anatomic variations.

$\mathrm{CB}$ is usually asymptomatic. However, an extensively pneumatized middle turbinate may constitute space-occupying mass, and thus, may cause nasal obstruction and impaired nasal breathing $(5,12)$. In our case, there was a large CB that almost completely obstructed the left nasal cavity. The patient had a severe septal deviation which caused nasal obstruction in the right side. After the surgical treatment, nasal breathing was significantly improved.

\section{Conclusion}

Doubly septated CB with four different sources of pneumatization is uncommon anatomic variation. CT scan afords easy identification of this intricate anatomy and complements endoscopic examination of the nasal cavity. Large CB which causes airway obstruction without associated sinus disease needs transnasal endoscopic surgical treatment.

\section{References}

1. Aktas D, Kalcioglu MT, Kutlu R, Ozturan O, Oncel S. The relationship between the concha bullosa, nasal septal deviation and sinusitis. Rhinology 2003;41:103-6.

2. Arslan H, Aydinlioglu A, Bozkurt M, Egeli E. Anatomic variations of the paranasal sinuses: CT examination for endoscopic sinus surgery. Auris Nasus Larynx 1999;26:39-48

3. Bhattacharyya N. Do maxillary sinus retention cysts reflect obstructive sinus phenomena? Arch Otolaryngol Head Neck Surg 2000;126:1369-71.

4. Bolger WE, Butzin CA, Parsons DS. Paranasal sinus bony anatomic variation and mucosal abnormalities: CT analysis for endoscopic sinus surgery. Laryngoscope 1991;101:56-64

5. Braun H, Stammberger H. Pneumatization of turbinates. Laryngoscope 2003; $113: 668-72$.

6. Eweiss A, Abo Khatwa MM, Zeitoun H. Trifurcate middle turbinate; an unusual anatomical variation. Rhinology 2008;46:246-8.

7. Hatipoglu HG, Cetin MA, Yüksel E. Concha bullosa types: their relationship with sinusitis, ostiomeatal and frontal recess disease. Diagn Interv Radio 2005; 11:145-9.

8. Kayalioglu G, Oyar O, Govsa F. Nasal cavity and paranasal sinus bony variations: a computed tomographic study. Rhinology 2000;38:108-13.

9. Krzeski A, Tomaszewska E, Jakubczyk I, Galewicz-Zielińska. Anatomic variations of the lateral nasal wall in the computed tomography scans of patients with chronic rhinosinusitis. Am J Rhinol 2001:15:371-5.

10. Lee HY, Kim CH, Kim JY, Kim JK, Song MH, Yang HJ, et al. Surgical anatomy of the middle turbinate. Clin Anat 2006;19:493-6.

11. Lin YL, Lin YS, Su WF, Wang CH. A secondary middle turbinate co-existing with an accessory middle turbinate: an unusual combination of two anatomic variations. Acta Otolaryngol 2006;126:429-31.

12. Stammberger H. Functional endoscopic surgery: Philadelphia: BC Decker, 1991.

13. Yanagisawa E, Mirante JP, Christmas DA. Endoscopic view of a septated concha bullosa. Ear Nose Throat J 2008;87:70-1.

14. Zinreich SJ, Mattox DE, Kennedy DW, Chisholm HL, Diffley DM, Rosenbaum AE. Concha bullosa: CT evaluation. J Comput Assist Tomogr 1988;12:778-84.

15. Zuckerkandl E. Normale und pathologishe anatomie der nasenhöhle und ihrer pneumatischen Anhange, $2^{\text {nd }}$ ed., Vienna: Braumüller, 1893. p. 368-400.

Received: $14 / 09 / 2009$.

Accepted in revised form: 24/09/2009.

\section{Corresponding author:}

Aleksandar Perić, Clinic for Otorhinolaryngology, Military Medical Academy, Crnotravska 17, 11040 Belgrade, Serbia; e-mail: alexneta@sezampro.rs 